\title{
Application of FEM simulation method in area of the dynamics of cooling AHSS steel with a complex hybrid welding process
}

\author{
Adam Sajek $^{1}$ (D)
}

Received: 6 July 2017 / Accepted: 22 February 2019 / Published online: 11 April 2019

(C) The Author(s) 2019

\begin{abstract}
The purpose of this paper is to present the course of a thermal cycle induced by welding in characteristic points in a joint and demonstrate the capabilities of simulation techniques with regard to thermal analysis of welding. Hybrid plasma-arc welding (HPAW) tests were conducted on samples of advanced high-strength steel (AHSS). Welding FEM analysis was carried out. Cooling time was determined for characteristic zones in the joint. The results of the simulation were then juxtaposed with the experimental data. Considerable diversification of the $t_{8 / 5}$ and $t_{8 / 3}$ times was observed for the analysed areas in the joint. The description of the thermal cycle presented in this paper questions the validity of analysing the changes occurring in the HAZ with the use of conventional TTT diagrams, extending the analysis of thermal conditions of a produced joint by new techniques of numerical prediction of thermal history of HPAW.
\end{abstract}

Keywords Welding $\cdot$ Modelling and simulation $\cdot$ Steel $\cdot$ Ultra high strength $\cdot$ Thermal analysis

\section{Introduction}

Numerical simulations provide information on physical phenomena which can be obtained in an experiment limited to the revision of calculations. This was confirmed by Stix et al. [1] who used in their research a specialist dedicated softwaresimufact.welding. Such applications have built-in functions responsible for defining heat sources, trajectories, fastening devices, multi-phase materials, etc. Methods of precise representation of different heat sources are still being researched. Wu et al. [2] proposed a new improved numerical model of a plasma heat source that encompassed the specificity of energy transfer within a stream of plasma gas.

Simulations in welding take into consideration every aspect of production of joints, along with their properties. It is possible to conduct an analysis of metal and heat dispersion in the weld pool during GMAW, which was done by Cheon et al. [3], or during HPAW (for heat sources aligned centrically along a

Recommended for publication by Commission IX - Behaviour of Metals Subjected to Welding

Adam Sajek

adam.sajek@zut.edu.pl

1 Department of Mechanical Engineering, West Pomeranian University of Technology, Piastow 19 St., 70-310 Szczecin, Poland single axis), which was done by Liu et al. [4]. Simulations of hybrid welding process focus mainly on the GMAW processes as well as the ones in which laser is used (hybrid laser-arc or arc-laser welding, depending on the order of heat sources). One example of such an experiment is the analysis of stresses and strains which was conducted by Zhan et al. [5], who were investigating the use of HALW process in terms of welding the Ni-Fe (invar36) alloy.

Simulations of the strength of welded joints that take into consideration the changes in the HAZ strength resulting from annealing and tempering are also conducted. Maurer, Panda, and Mochizuki et al. [6-8] performed quasi-static simulations of a HAZ with a diversified microstructure, which allowed them to determine the influence of a relative thickness of the tempered zone on the properties of the joints.

On the basis of a simulation, Goldak et al. [9] showed that when the amount of supplied heat is constant, one can find a correlation between welding speed and the thermal effect that can be observed in the HAZ.

Simulations can also be a source of data that can be used for training artificial neural networks. Yu and Krajewski et al. $[10,11]$ created such a network that was later used for the prediction of hardness on the basis of technological parameters.

The number of works dedicated to HPAW process simulations is scarce. So far, this issue has been taken up by Nowacki 
et al. [12] who made an attempt to determine thermal cycle conditions. There is a need to extend the knowledge concerning simulations of hybrid welding that makes use of a complex heat source, i.e. one that includes a plasma source and a classical one.

The subject area of high-efficiency welding of advanced high-strength steels is one of the mainstream issues in contemporary welding. It encompasses questions related to the weldability of advanced high-strength steel (AHSS) and the possibilities for employing innovative welding technologies in the process of joining thereof.

Specific processability and performance of such materials can be obtained by proper doping and complex heat and thermo-mechanical treatment (Fig. 1) [13].

AHSS can also include second-generation steels that are characterised not only by their high strength but also by their very high plasticity. The steels encompass duplex type ferriticaustenitic steels with the addition of manganese as an ingredient that stabilises austenite as well as steels with the TWIN and TRIP effects. The third-generation AHSSs that are currently being developed are characterised by a more advantageous strength-plasticity ratio than the first-generation steels and by a lower price than the second-generation AHSS [14-18].

AHSSs are used when the mass-loading capacity ratio is of high importance for the attractiveness of a construction. Welding is considered a natural method of joining in this area; however, the negative influence of supplied heat on the properties of steel prone to annealing constitutes a major disadvantage [19-21]. The parameter that characterises the amount of heat supplied into the joint is the cooling time in the temperature range between 800 and $500{ }^{\circ} \mathrm{C}$, marked as $\mathrm{t}_{8 / 5}$. In the case of advanced

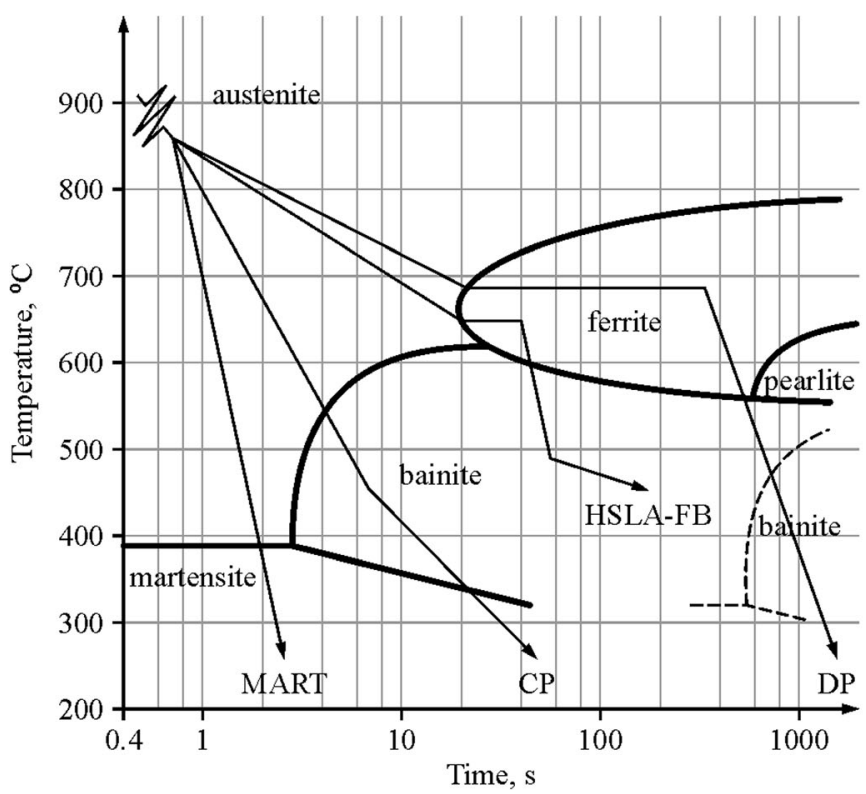

high-strength steels, the span of $t_{8 / 5}$ values becomes significantly limited, edging towards low values. The structure of AHSS - shaped in the complex process of thermomechanical treatment-should remain as unspoilt by the welding heat as possible (Fig. 2) [22-27].

Such a situation triggers the development of welding techniques, and it consists in decreasing the amount of supplied heat while keeping the weld metal fusion coefficient at a high level. In recent years, a lot of processes that maximise electrode fusion have emerged. In effect, high welding speeds can be obtained, which results in the production of more favourable properties of the joints. Another step on the way to improve the thermal balance is combining different welding processes within a single head. A combination of a high-energy laser or plasma heat source with a source that would ensure efficient filling of the weld groove in the GMAW process seems to be the only way to fulfil the increasingly strict requirements. In hybrid processes, it is possible to obtain extremely high welding speeds while at the same time reducing the number of runs to a single one, even when the thickness of a material exceeds $10 \mathrm{~mm}[28,29]$

\section{Prediction of cooling time of a welded joint}

The analysis of the capabilities of simulation methods in terms of prediction of cooling time of a HPAW joint was based on seven experiments that involved welding model joints and making an attempt at modelling the whole process.

Model butt joints were made from S960QL and S1300QL steels (Table 1) and bevelled so as to produce a single $20^{\circ} \mathrm{V}$ groove. Nonlinear thermal characteristics of materials based

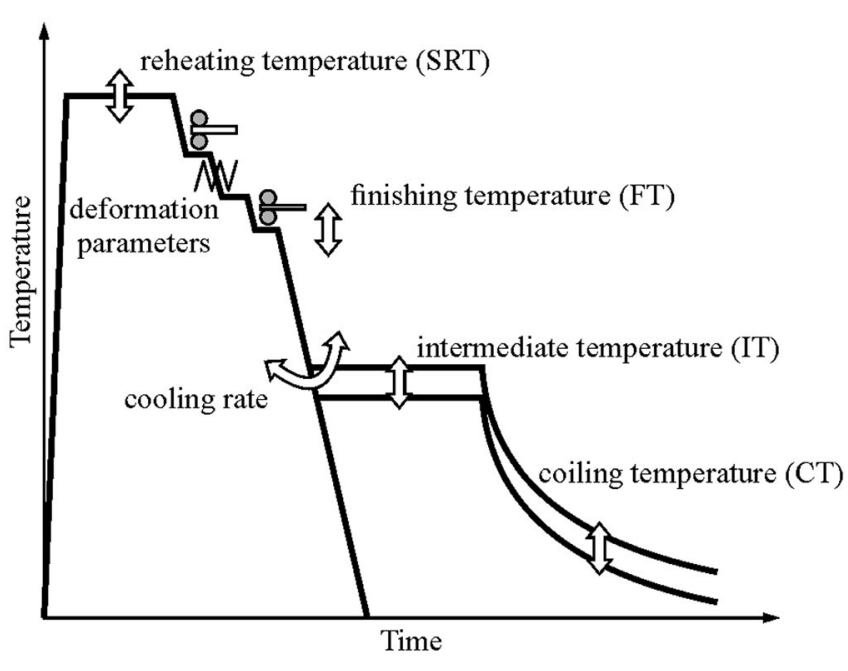

Fig. 1 The mechanisms of heat treatment and thermo-mechanical treatment of selected grades of steels that are currently in production 
Fig. 2 Construction steels and recommended values of $t_{8 / 5}$ cooling time. Classical steels: interstitial free, if high strength, mild steels, bake hardenable, high-strength low-alloy/ferriticbainitic. Stale AHSS: dual phase, transformation-induced plasticity, complex phase, twinning induced plasticity $\mathrm{MnB}+\mathrm{HF}$ (doped with manganese and boron, hardened hot forming), martensitic (MART)

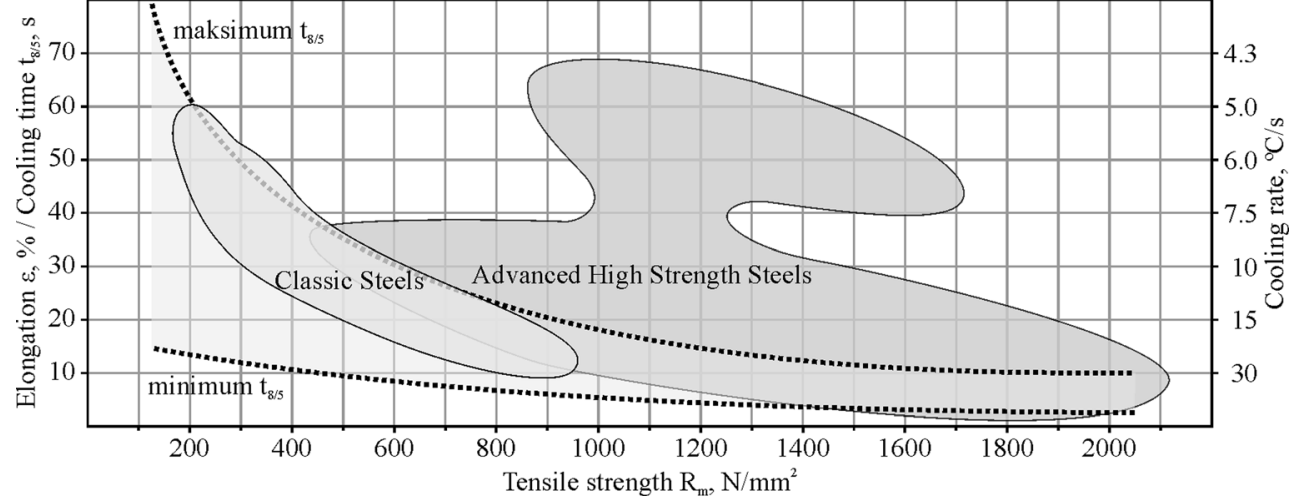

Fusion zone was represented as a diagram of maximum temperature value on the cross-section, located midway along the length of the joint. In this case, the white area representing the temperature that exceeds melting point marks the boundary of the weld (Fig. 8).

The simulation method made is possible to characterise thermal history in any given point in the joint. After delineating the fusion line for each sample, temperature changes in the HAZ were investigated. A point located $2 \mathrm{~mm}$ from fusion line and $3 \mathrm{~mm}$ beneath the surface of the plate was adopted as a representative spot (Fig. 9).

It is possible to determine the $t_{8 / 5}$ time in the point analysed in Fig. 9 only for the B18-30 sample that was welded with twice as high heat input than the previous one. In order to make it possible to compare the processes, the $t_{6 / 3}$ times were determined as well.

Depending on the amount of heat supplied, the maximum temperatures $\left(660-1040^{\circ} \mathrm{C}\right)$ change and so does the cooling dynamics in the temperature range of $600-300{ }^{\circ} \mathrm{C}$ $(10-24.5$ s). Consequently, the HAZ becomes narrower and moves towards the fusion line.

Figure 9 shows slight disparities between the A (S960QL) and B (S1300QL) samples resulting from their having different thicknesses, material properties, and interpolations made between the mesh nodes where the analysed point was located.

The thermal history of the following characteristic points in the joints was analysed:

- FZ - point no. 1 located on the axis of the joint (fusion zone) above $1510{ }^{\circ} \mathrm{C}$;

The simulations were carried out in accordance with the plan enon of weld overlap (Fig. 7).

Table 1 Properties of the analysed materials

\begin{tabular}{lll}
\hline Steel name & S960QL & S1300QL \\
Producer name & XABO® 960 ThyssenKrupp & WELDOX 1300 E SSAB \\
Yield strength, min MPa & 960 & 1300 \\
Tensile strength, MPa & $980-1150$ & $1400-1700$ \\
Elongation, $\%$ & 12 & 8 \\
\hline
\end{tabular}




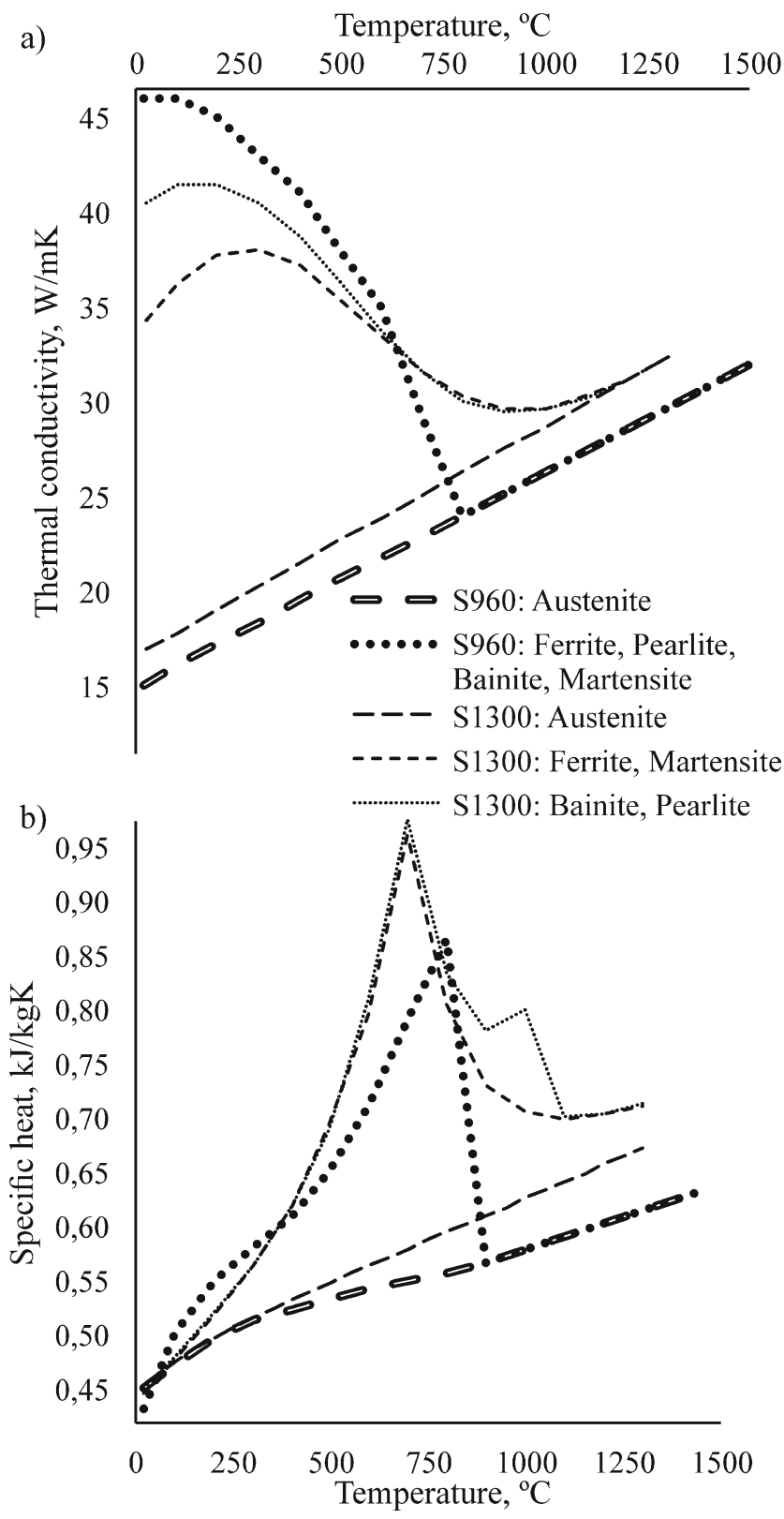

Fig. 3 Implemented in FEM environment, temperature-based nonlinear, thermal characteristics of multi-phase materials. a) Thermal conductivity. b) Specific heat

- $\mathrm{FL}$ - fusion line of the temperature of $1510{ }^{\circ} \mathrm{C}$;

- $\mathrm{SZ}$ - annealed soft zone in the temperature range of $600-700{ }^{\circ} \mathrm{C}$;

- $\mathrm{PM}$ - an area of partly decrystallised parent material, located right outside the $\mathrm{HAZ}$ below $500{ }^{\circ} \mathrm{C}$.

The points were selected considering the shifting maximum temperature fields (Fig. 10) that moved due to varying amount of supplied heat. Since only minor differences were observed in the cooling dynamics of the A and B samples (Fig. 9), it were the S1300QL (B) samples that underwent further analyses.
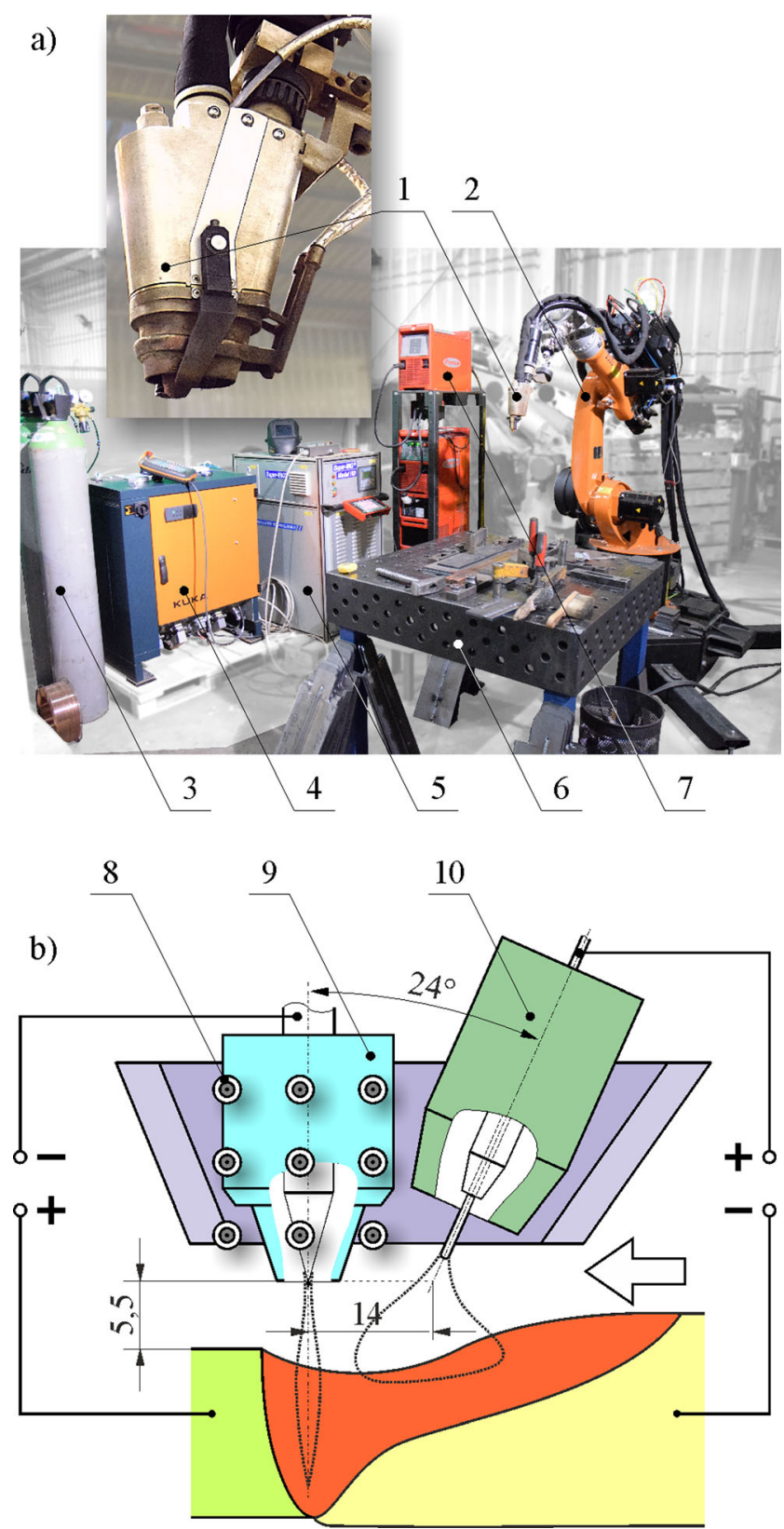

Fig. 4 Schemes of the robotic welding station (a) and HPAW hybrid welding head (b) used in research. 1: HPAW welding head; 2: robotized manipulator; 3: plasma and shielding gas cylinders; 4: manipulator power source and control panel; 5: plasma power source; 6: welding table; 7: GMAW power source; 8: arcs positioning system (constant magnetic field generator); 9: plasma torch; 10: GMAW torch

The determinable $t_{8 / 5}$ time comprises the weld as well as a narrow adjacent zone. Figure 9 shows that in order to register a temperature exceeding $800^{\circ} \mathrm{C}$ at a distance of $2 \mathrm{~mm}$ from the fusion line, it is necessary to supply a considerable amount of heat into the joint. In our case, it was possible when welding parameters generated the amount of heat that exceeded $9 \mathrm{~kJ} /$ $\mathrm{cm}$. Obtaining such temperature in the soft zone seems difficult to achieve. 
Table 2 The parameters of hybrid welding process for the analysed joints

\begin{tabular}{lllcc}
\hline Sample & Base material & $Q_{\mathrm{c}}, \mathrm{kJ} / \mathrm{cm}$ & $T_{0},{ }^{\circ} \mathrm{C}$ & $v_{\mathrm{w}}, \mathrm{cm} / \mathrm{min}$ \\
\hline A6-20 & S960QL \#10.0 & 6 & 20 & 70 \\
B6-20 & S13000QL \#9.5 & 6 & 20 & 70 \\
A8-100 & S960QL \#10.0 & 8 & 100 & 85 \\
B8-100 & S13000QL \#9.5 & 8 & 100 & 85 \\
A9-180 & S960QL \#10.0 & 9 & 180 & 100 \\
B9-180 & S13000QL \#9.5 & 9 & 180 & 100 \\
B18-30 & S13000QL \#9.5 & 18 & 35.0 & 50 \\
\hline
\end{tabular}

A temperature that is easier to obtain in the whole HAZ is the temperature of $600{ }^{\circ} \mathrm{C}$. It is high enough to trigger the tempering of martensite which is the main structural ingredient in AHSS of MART type. In order to quantify cooling dynamics in the HAZ in martensitic steels, it is more accurate to consider cooling time in a lower range of temperatures, i.e. up to $300{ }^{\circ} \mathrm{C}$ which is the borderline temperature for lowtemperature tempering that the steel underwent in the manufacturing process. The $t_{6 / 3}$ time is more adequate for

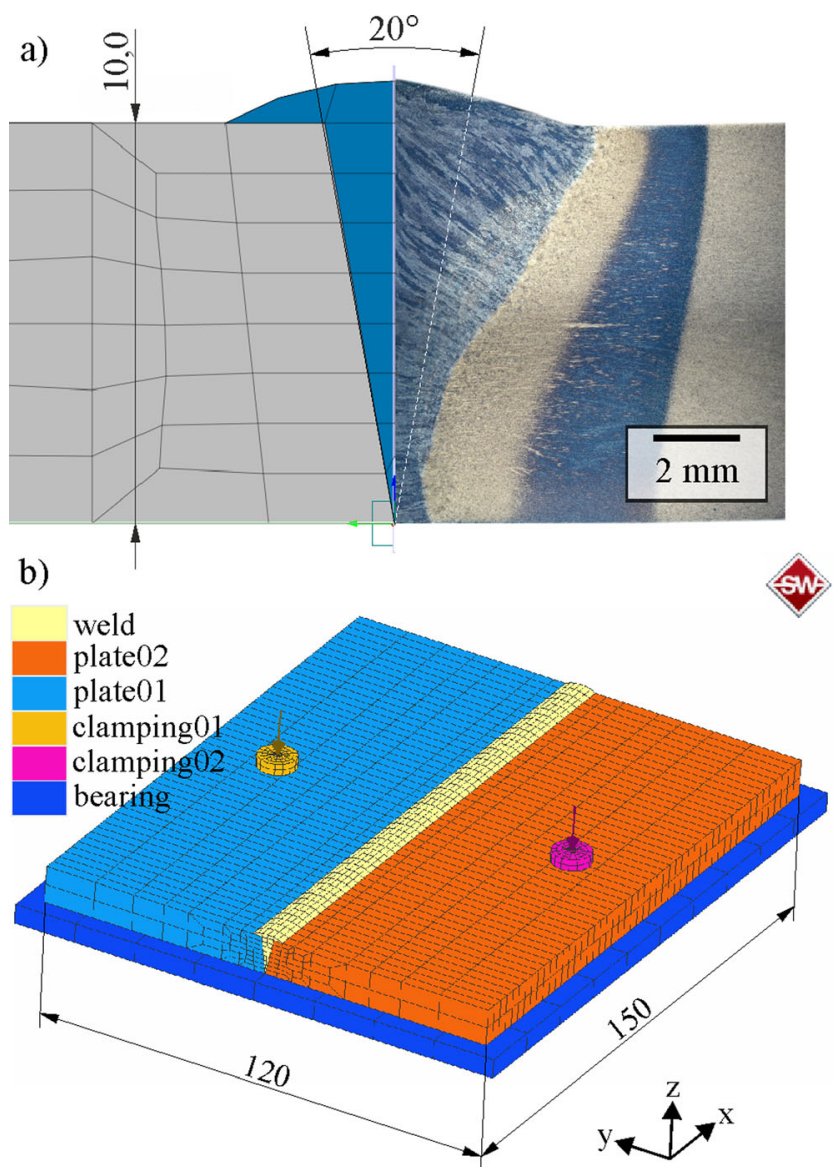

Fig. 5 An example of a finite element mesh created on the basis of the B9-180 joint (a) and the boundary conditions of simulation (b) min. element size, $0.5 \mathrm{~mm}$; clamping force $\mathrm{z}$-direction, $50 \mathrm{~N}$ other AHSS presented in this paper, whose martensitic structure is prone to annealing (Fig. 1).

Obtaining a thorough joint penetration for the HPAW process when the $t_{8 / 5}$ time is lower than $10 \mathrm{~s}$ (as it is recommended) proves impossible. It is only possible to obtain such a value in case of multi-pass GMAW. This process, however, is not recommended due to the destructive influence the complex thermal cycle has on the strength of a joint. It is important to determine welding parameters that guarantee obtaining an appropriate joint without supplying too much heat in a very precise way. The problem can be solved by computer simulations. Further research on hybrid heat source is needed in order to fully reproduce the actual welding conditions.

\section{Summary}

Having analysed the results of the experiments, the following conclusions were drawn:

(1) Simulation methods allow to characterise the thermal cycle in any given point in the weld, with the use of any given geometry of the welded joint and a wide range of more or less complex heat sources. Therefore, it is possible to examine the complete thermal history of the joint area and to interpret the phenomena occurring in its structure correctly.

(2) A parameter characterising the structure of the HAZ in MART steel and its proneness to tempering in a direct way is the $t_{6 / 3}$ time. Contrary to the $t_{8 / 5}$ time, the $t_{6 / 3}$ time can be determined in the whole HAZ and has a more stable cooling dynamics.

(3) The minimum range of welding parameters for the analysed joint geometry was established. The parameters generate slightly different cooling times when entered into the software than the cooling times observed in the experiment. It is due to the fact that it is difficult to estimate the amount of heat supplied solely on the basis of the values of voltage and current parameters registered by the welding devices. In order to determine the values of these parameters in an unambiguous way, it is necessary to establish the thermal characteristics of a hybrid heat source in an experiment, which will be the object of further research.

(4) When appropriate material definitions are employed, i.e. ones including temperature characteristics of a multiphase structure, it is possible to visualise such properties of a joint as phase composition, hardness, state of stresses, and strains, and to shape them depending on welding parameters. Due to specialist welding FEM software, it is possible to determine optimum parameters in welding advanced construction materials using modern, highly efficient methods. 

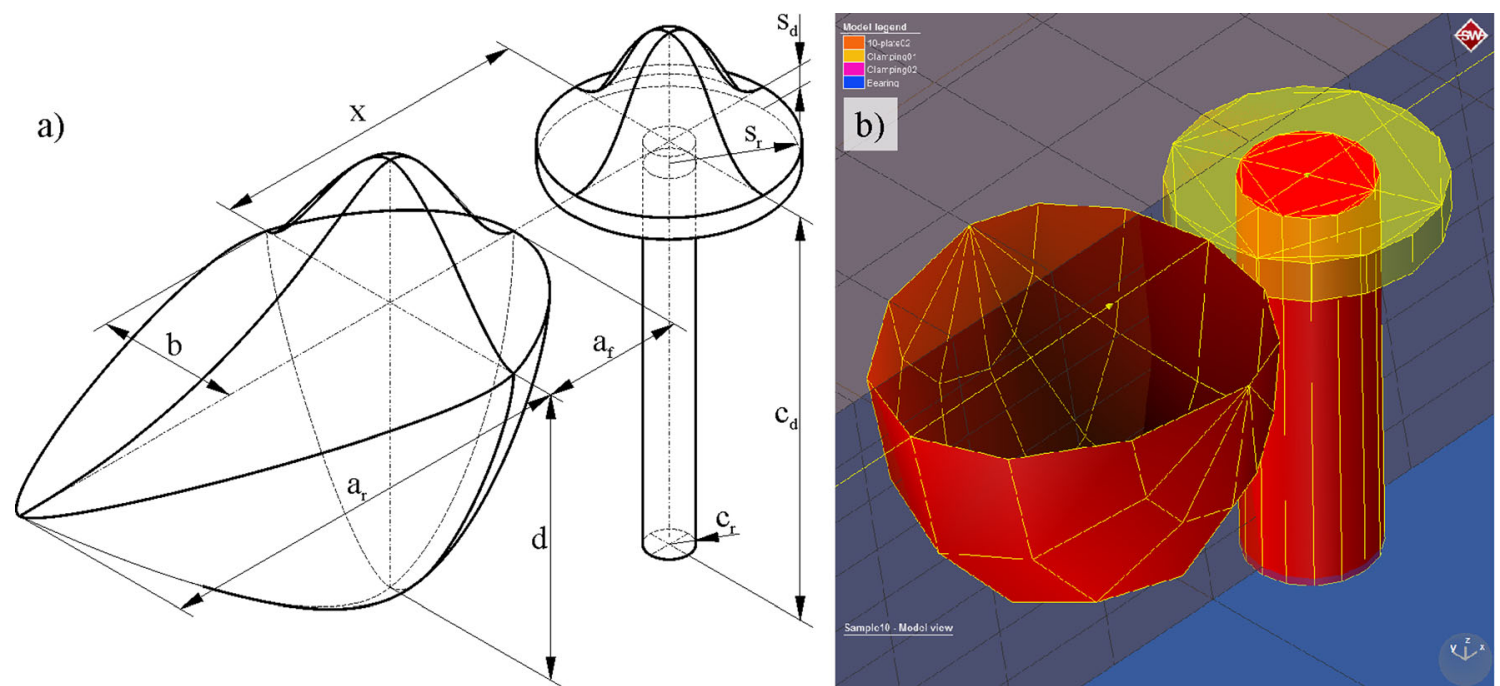

Fig. 6 Hybrid heat model employed in the simulation. Characteristic dimensions (a) and an image of the heat source as defined in the simufact.welding software (b)

Table 3 Heat source parameters for each sample series. Constant parameters for plasma process: cylinder heat fraction $=0.8$; efficiency $=$ 0.8 ; cylinder depth $(\mathrm{cd})=10 \mathrm{~mm}$; and for GMAW: heat front scaling factor $=0.8$. Other plasma parameters: $P$, power; $c_{\mathrm{r}}$, cylinder radius; $S_{\mathrm{r}}$, heat source radius; $S_{\mathrm{d}}$, surface depth; and GMAW: $a_{\mathrm{f}}$, front length; $a_{\mathrm{r}}$, rear length; $b$, width; $d$, depth (Fig. 6a)

\begin{tabular}{llllllll}
\hline Series & $\begin{array}{l}P, \mathrm{~W} \\
\text { Plasma }\end{array}$ & $c_{\mathrm{r}}, \mathrm{mm}$ & $\mathrm{S}_{\mathrm{r}}, \mathrm{mm}$ & $S_{\mathrm{d}}, \mathrm{mm}$ & $\begin{array}{l}a_{\mathrm{f}}, \mathrm{mm} \\
\text { GMAW }\end{array}$ & $a_{\mathrm{r}}, \mathrm{mm}$ & $b, \mathrm{~mm}$ \\
\hline $6-20$ & 4744 & 1.3 & 2.6 & 0.8 & 2.6 & 5.0 & 3.6 \\
$8-100$ & 6720 & 1.4 & 2.8 & 0.9 & 2.8 & 5.5 & 3.8 \\
$9-180$ & 8189 & 1.5 & 3.0 & 1.0 & 3.0 & 6.0 & 6.0 \\
$18-30$ & 8016 & 1.5 & 3.0 & 1.0 & 3.0 & 6.0 & 7.0 \\
\hline
\end{tabular}

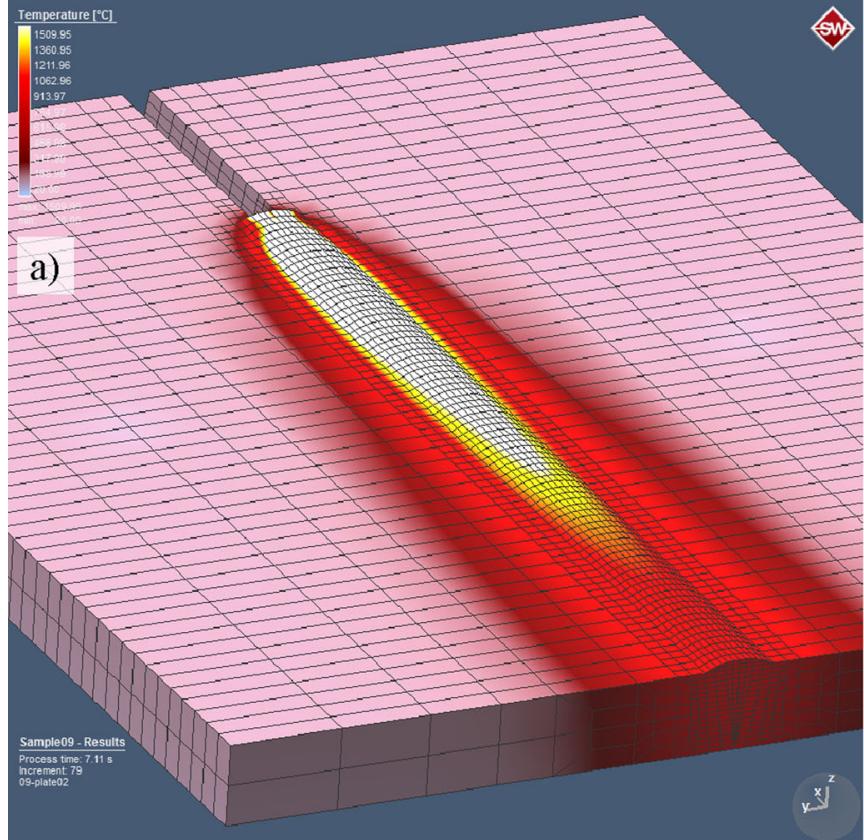

Fig. 7 The result of the numerical simulation of welding the B9-180 sample. Isometric view of the welded fragment of the joint (a) and section view (b) showing the pool of molten metal and executed function "mesh

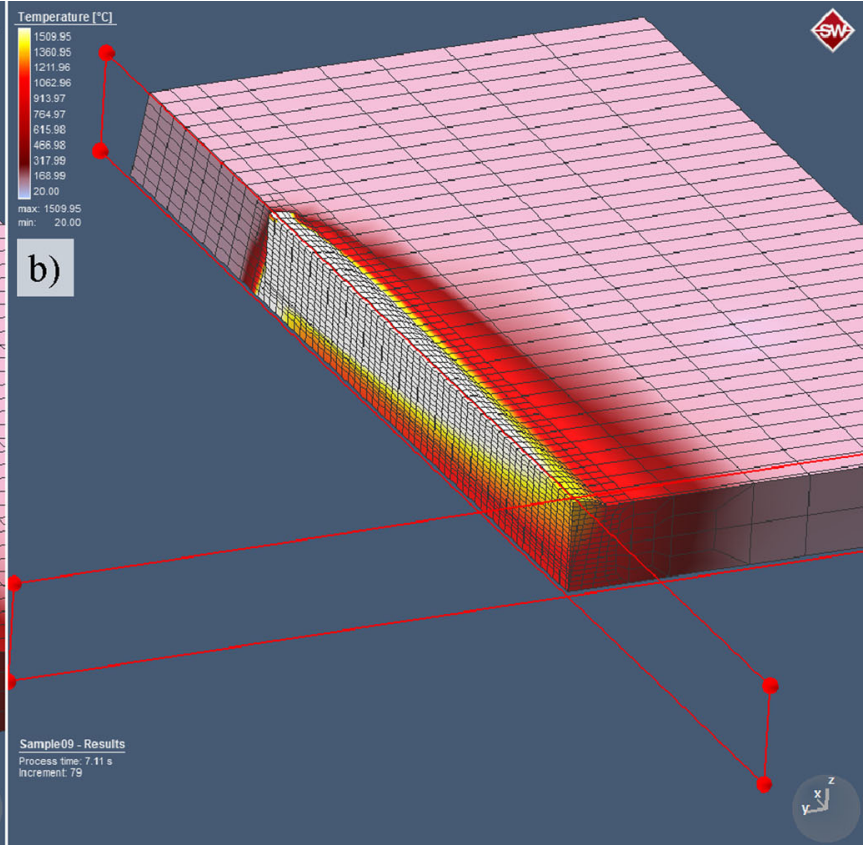

refinement" increasing mesh density around the moving heat source (min. element size, $0.25 \mathrm{~mm}$ ) 
Fig. 8 A comparison of fusion determined by means of FEM juxtaposed with the actual fusion in the B9-180 sample

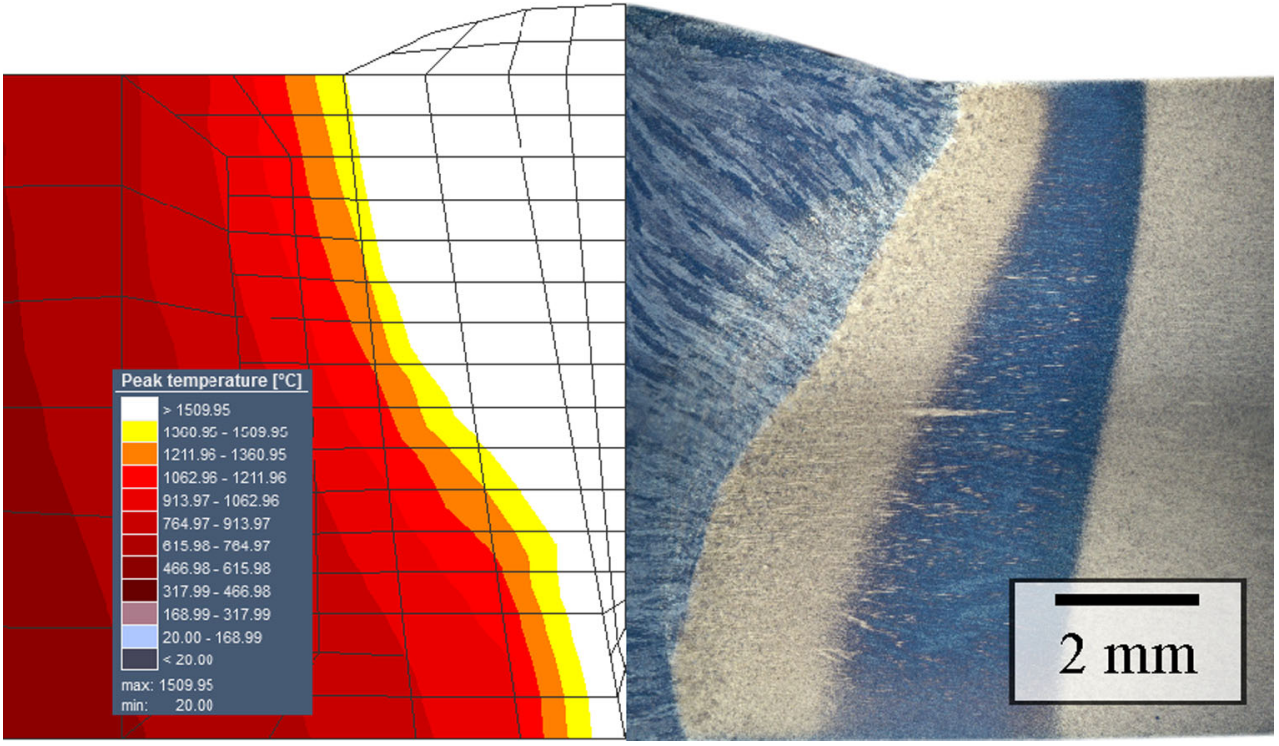

Fig. 9 Temperature course for the point located $2 \mathrm{~mm}$ from fusion line and $3 \mathrm{~mm}$ beneath the surface of the plate

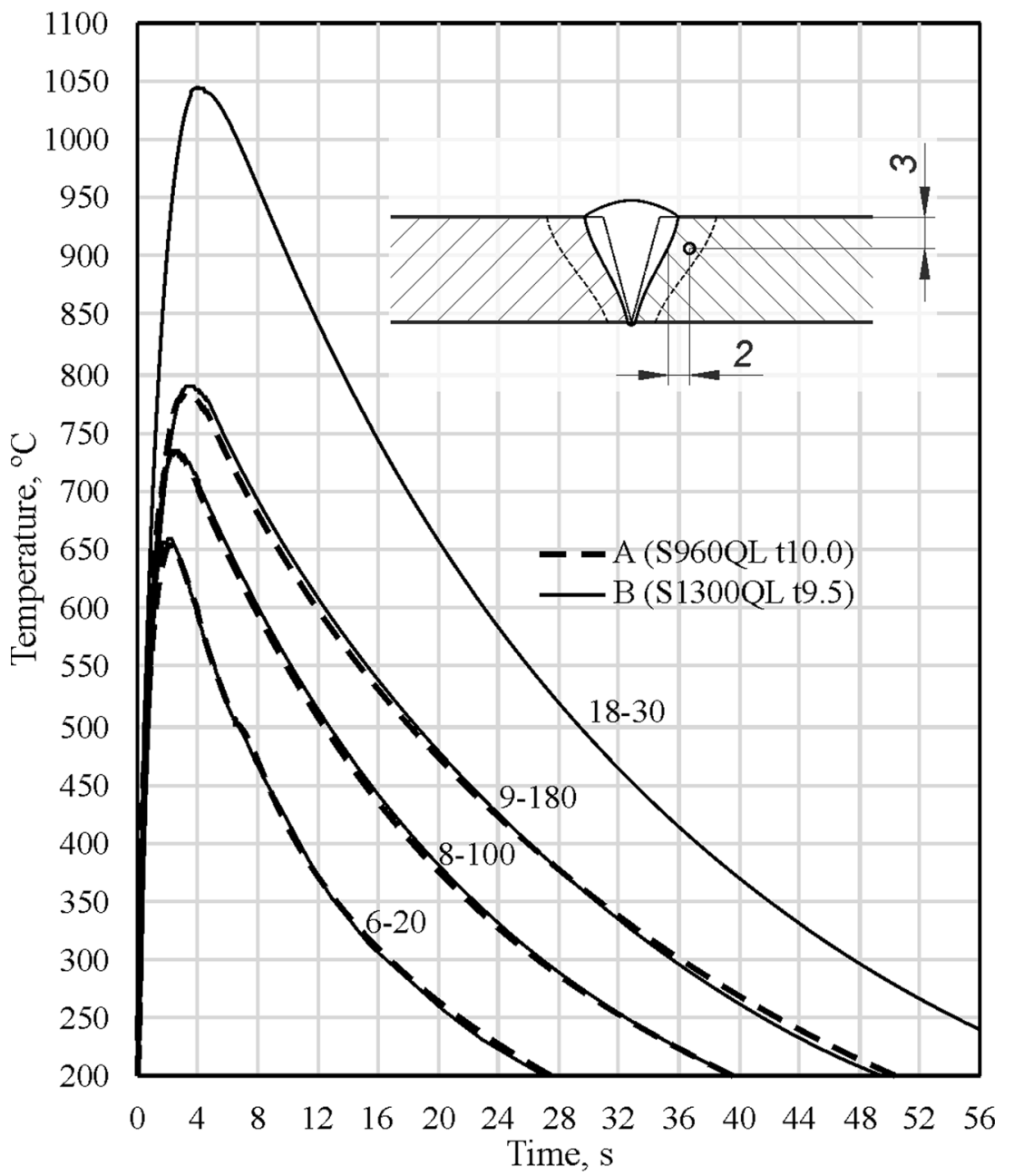


Fig. 10 Temperature course for characteristic points in the joints of S1300QL (B6-20 and B8-180) steel

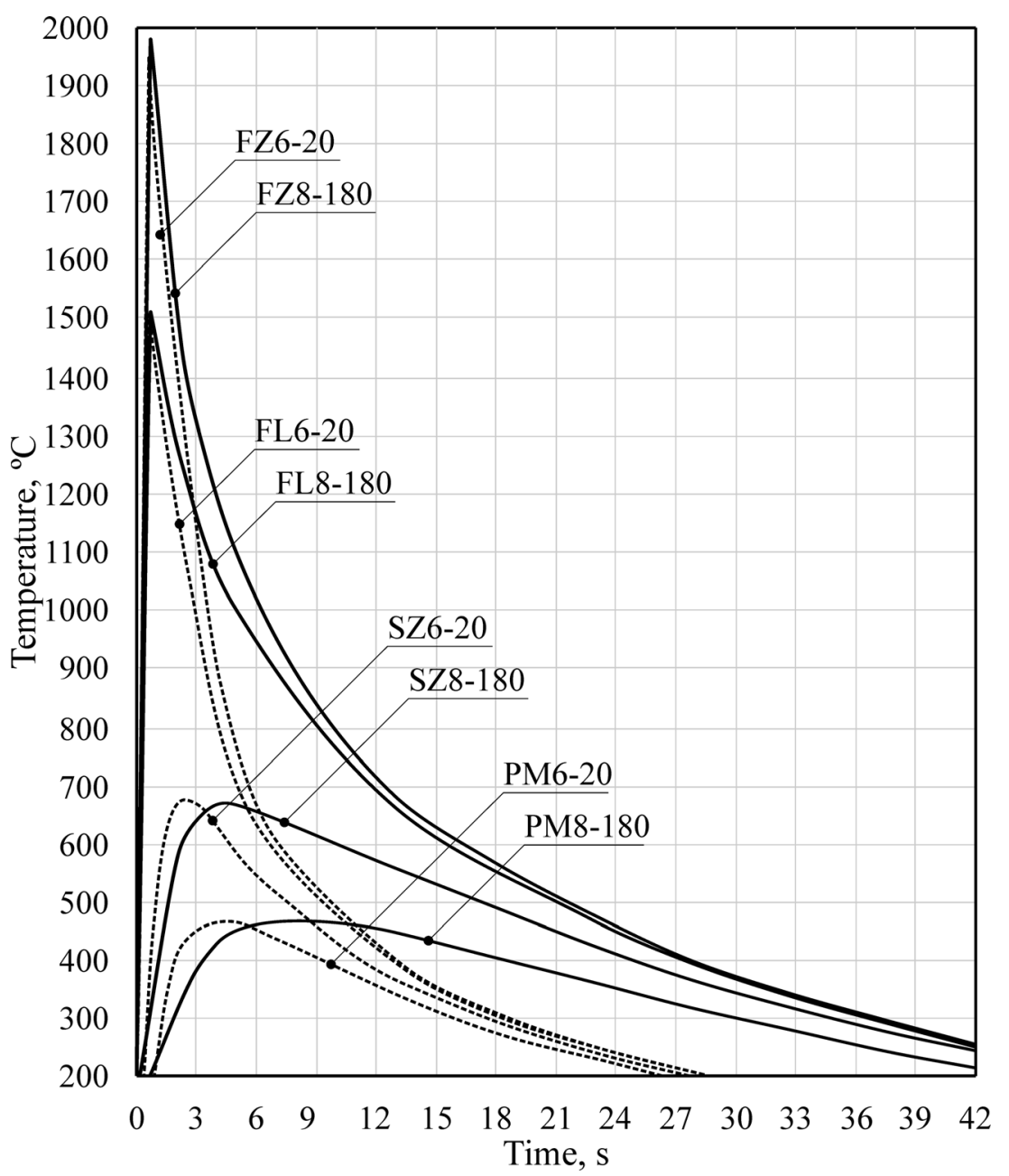

Open Access This article is distributed under the terms of the Creative Commons Attribution 4.0 International License (http:// creativecommons.org/licenses/by/4.0/), which permits unrestricted use, distribution, and reproduction in any medium, provided you give appropriate credit to the original author(s) and the source, provide a link to the Creative Commons license, and indicate if changes were made.

\section{References}

1. Stix G, Buchmayr B (2015) Investigation of residual stresses and distortions produced in tubular. IIW Int Conf High-Strength Mater Challenges Appl 1-5

2. Wu CS, Wang HG, Zhang YM (2006) A new heat source model for keyhole plasma arc welding in FEM analysis of the temperature profile. Weld J 85:284-291

3. Cheon J, Kiran DV, Na S-J (2016) CFD based visualization of the finger shaped evolution in the gas metal arc welding process. Int $\mathrm{J}$ Heat Mass Transf 97:1-14. https://doi.org/10.1016/j. ijheatmasstransfer.2016.01.067
4. Liu ZM, Cui SL, Luo Z, Zhang CZ, Wang ZM, Zhang YC (2016) Plasma arc welding: process variants and its recent developments of sensing, controlling and modeling. J Manuf Process 23:315-327. https://doi.org/10.1016/j.jmapro.2016.04.004

5. Zhan X, Li Y, Ou W, Yu F, Chen J, Wei Y (2016) Comparison between hybrid laser-MIG welding and MIG welding for the invar36 alloy. Opt Laser Technol 85:75-84. https://doi.org/10.1016/j. optlastec.2016.06.001

6. Maurer W, Ernst W, Rauch R et al (2013) Numerical simulation on the effect of HAZ softening on static strength of HSLA steel welds. In: Sommitsch C, Enzinger N (eds) Math. Model. Weld Phenom, vol 10. Verlag der Technischen Universität Graz, Graz, pp 669-690

7. Panda SK, Kuntz ML, Zhou Y (2009) Finite element analysis of effects of soft zones on formability of laser welded advanced high strength steels. Sci Technol Weld Join 14:52-61. https://doi.org/10. 1179/136217108X343920

8. Mochizuki M, Shintoni T, Hashimoto Y, Toyoda M (2004) Analytical study on deformation and strength in HAZ-softened welded joints of fine-grained steels. Weld world 48:2-12. https:// doi.org/10.1007/BF03263396

9. Goldak J, Asadi M, Alena RG (2010) Why power per unit length of weld does not characterize a weld? Comput Mater Sci 48:390-401. https://doi.org/10.1016/j.commatsci.2010.01.030 
10. Yu L, Kameyama M, Hirano S, et al (2015) Neural network-based hardness and toughness prediction in HAZ of temper bead welding repair technology. IIW Int Conf High-Strength Mater - Challenges Appl 1-7

11. Krajewski S, Nowacki J (2014) Dual-phase steels microstructure and properties consideration based on artificial intelligence techniques. Arch Civ Mech Eng 14:278-286. https://doi.org/10.1016/ j.acme.2013.10.002

12. Nowacki J, Sajek A (2016) Numerical simulation of the thermal cycle of the PAW-MAG hybrid welding of advanced high strength steels heat distribution in PAW-MAG. Inst Weld Bull 60:13-19. https://doi.org/10.17729/ebis.2016.6/2

13. Spindler H, Klein M, Rauch R et al (2012) High strength and ultra high strength hot rolled steel grades - products for advanced applications. BHM Berg- und Hüttenmännische Monatshefte 157:108112

14. Sohn SS, Choi K, Kwak J et al (2014) Novel ferrite-austenite duplex lightweight steel with $77 \%$ ductility by transformation induced plasticity and twinning induced plasticity mechanisms. Acta Mater 78:181-189. https://doi.org/10.1016/j.actamat.2014.06.059

15. Grajcar A, Kuziak R, Zalecki W (2012) Third generation of AHSS with increased fraction of retained austenite for the automotive industry. Arch Civ Mech Eng 12:334-341. https://doi.org/10.1016/j. acme.2012.06.011

16. Martis CJ, Putatunda SK, Boileau J (2013) Processing of a new high strength high toughness steel with duplex microstructure (ferrite+austenite). Mater Des 46:168-174. https://doi.org/10.1016/j. matdes.2012.10.017

17. Aydin H, Essadiqi E, Jung I-H, Yue S (2013) Development of 3rd generation AHSS with medium Mn content alloying compositions. Mater Sci Eng A 564:501-508. https://doi.org/10.1016/j.msea. 2012.11.113

18. Herrera C, Ponge D, Raabe D (2011) Design of a novel Mn-based 1 GPa duplex stainless TRIP steel with $60 \%$ ductility by a reduction of austenite stability. Acta Mater 59:4653-4664. https://doi.org/10. 1016/j.actamat.2011.04.011

19. Keeler S, Kimchi M (2014) Advanced high strength steels for automotive industry. WorldAutoSteel 5:200-215. https://doi.org/10. 1016/S1644-9665(12)60197-6

20. Fiedler M, Rauch R, Schnitzer R, et al (2015) The alform ${ }^{\circledR}$ welding system. The world's first system for high-strength welded structures. IIW Int Conf High-Strength Mater - Challenges Appl 1-5
21. Porter DA (2015) Weldable high-strength steels: challenges and engineering applications. IIW Int Conf High-Strength Mater Challenges Appl:1-13

22. Schneider C, Ernst W, Schnitzer R et al (2016) Influence of different welding processes on the mechanical properties of structural steel S960MC. Thermec Graz 1

23. Banerjee K (2016) Improving weldability of an advanced high strength steel by design of base metal microstructure. J Mater Process Technol 229:596-608. https://doi.org/10.1016/j. jmatprotec.2015.09.026

24. Matlock DK, Speer JG (2008) Third generation of AHSS: microstructure design concepts. In: Haldar A, Suwas S, Bhattacharjee D (eds) Int. Conf. Microstruct. Texture Steels Other Mater. Springer, Jamshedpur, India, pp 187-205

25. Billur E, Cetin B, Gurleyik M (2016) New generation advanced high strength steels: developments, trends and constraints. Int J Sci Technol Res 2:50-62

26. Fydrych D, Łabanowski J, Rogalski G (2013) Weldability of high strength steels in wet welding conditions. Polish Marit Res 20:6773. https://doi.org/10.2478/pomr-2013-0018

27. Certilas Nederland BV (2015) Cooling times (Delta T8/5) S355 till S960 | Certilas. http://www.certilas.nl/en/content/cooling-timesdelta-t85-s355-till-s960. Accessed 21 Jun 2015

28. Yurtisik K, Tirkes S, Dykhno I, Gur CH, Gurbuz R (2013) Characterization of duplex stainless steel weld metals obtained by hybrid plasma-gas metal arc welding. Soldag Inspeção 18:207216. https://doi.org/10.1590/S0104-92242013000300003

29. Fiedler M, Plozer A, Rutzinger B, Scherleitner W (2016) Control of mechanical properties of high strength steels through optimized welding processes. Inst Weld Bull 60:31-37. https://doi.org/10. 17729/ebis.2016.5/4

30. Goldak J, Chakravarti A, Bibby M (1984) A new finite element model for welding heat sources. Metall Trans B 15:299-305. https://oi.org/10.1007/BF02667333

Publisher's note Springer Nature remains neutral with regard to jurisdictional claims in published maps and institutional affiliations. 